\begin{abstract}
Following Hall (1997) it is increasingly common to incorporate preference, as well as productivity, perturbations in calibrated general equilibrium models. We assess the performance of a small open economy stochastic growth model (based on the BlanchardYaari framework) under alternate driving processes. Whilst both models provide familiar descriptions of the aggregate economy, we find that the model driven by productivity disturbances has clear advantages in explaining the behaviour towards foreign asset accumulation.
\end{abstract}

JEL classification: E20; E32; F32; F41.

Keywords: Intertemporal macro; Open economy; current account dynamics. 


\title{
Productivity and Preferences in a Small Open Economy ${ }^{1}$
}

\author{
Jagjit S. Chadha ${ }^{2}$, Norbert Janssen ${ }^{3}$ and Charles Nolan ${ }^{4}$
}

\section{Introduction}

Most macroeconomic variables display periodic fluctuations, sometimes around a rising trend. Much of this variation occurs within the so-called business cycle frequencies - that is, fluctuations predominating between eight and 32 quarters. Beginning with the seminal papers of Long and Plosser (1983) and Kydland and Prescott (1982), an important strand of macroeconomic research has successfully attempted to construct small, theoretically coherent, models based on optimizing agents which capture key patterns in the actual data. In this paper, we follow the analyses of Backus, Kehoe and Kydland (1989), Baxter and Crucini (1990) and Cardia (1991) and extend the stochastic growth model to the case of the open economy.

Specifically we develop two distinct models of a small open economy, which nevertheless share many similar characteristics. They are both inhabited by a corporate sector and a large number of individuals who face finite lives. ${ }^{5}$ Both model economies face an exogenous real interest rate determined in a perfectly integrated world capital market, and both economies have access to this market for their portfolio allocation decisions. However, these economies differ in what makes them grow stochastically through time. In one model the driving process is stochastic variation in a productivity shift term, while in the other it is period by period changes in the relative attractiveness of consumption versus leisure (see e.g., Hall (1997). ${ }^{6}$ Incorporating preference shocks has become increasingly

\footnotetext{
${ }^{1}$ Acknowledgements: We are grateful for helpful conversations, constructive criticisms and comments from participants in seminars at which versions of this paper were presented, including the Bank of England; University of Cambridge; Royal Economic Society 2000 Meeting at the University of St. Andrews; and the Money, Macro and Finance Conference 2000 at South Bank University. Any views expressed, or errors which remain, are solely the responsibility of the authors and do not necessarily represent those of their respective institutions. This paper was largely completed when Norbert Janssen was at London Guildhall University. We gratefully acknowledge the research assistance of Wesley Fogel. Part of this research has been funded by Leverhulme Grant no. F/09567/A.

${ }^{2}$ Department of Applied Economics, Austin Robinson Building, Sidgwick Avenue, Cambridge CB3 9DE. Tel: +44 1223 335280. E-mail: jagjit.chadha@econ.cam.ac.uk

${ }^{3}$ Bank of England, Threadneedle Street, London EC2R 8AH. Tel: +44 207601 4523. E-mail: norbert.janssen@bankofengland.co.uk.

${ }^{4}$ Department of Economics and Finance, University of Durham, 23/26 Old Elvet, Durham DH1 3HY. Tel: +44 191372 7273. E-mail: charles.nolan@durham.ac.uk.

${ }^{5}$ Specifically, there are overlapping generations, or cohorts, each facing a constant probability of death. See Blanchard (1985) and Yaari (1965).

${ }^{6}$ Hall (1997) strongly suggests considering the role of variation in agents' choices between work and leisure rather than the investment decisions, which are stressed by productivitiy shifts, in explaining business cycle variation.
} 
popular in quantitative theory. For example, Hall (op. cit) emphasizes the role of preference shocks as a crucial primitive in business cycle impulses. Woodford (2000), albeit in a closed economy, discusses the role of preference shocks. However, there has been relatively little effort to compare the performance of these models under alternate driving processes and consequently that is the aim of this paper.

Modelling the open economy is important for at least two reasons. First, the ability to alter holdings of net foreign assets in response to shocks provides an important adjustment mechanism. As a result and second, it provides us with an additional dimension along which to measure the importance of competing driving processes for our model. This aspect turns out to be particularly important in the case of a small open economy such as the UK. Chadha, Janssen and Nolan (2000) study the UK business cycle from 1871 to 1997 and find that many stylized facts of the post-war era are not robust to a pre-war sample period. ${ }^{7}$ However, one of the robust stylized facts for the UK is the high volatility and strong degree of countercyclicality in the current account.

In fact, the cyclical behavior of the current account has been the subject of much recent work. It is typically rationalized by an intertemporal approach to the current account (Obstfeld and Rogoff (1995)), and as the result of forward-looking households consuming the present value of permanent income, with the latter a nonstationary (stochastic) process. However, while the present value tests which grew out of the literature on consumption theory (Campbell (1987)) have delivered valuable insights, they have failed to provide a convincing explanation of the moments in the current account for small open economies, particularly in the case of the UK. For example, Obstfeld and Rogoff (1996) argue that the near random walk in output growth makes permanent income practically unforecastable and inexorably implies little cyclical variation in the current account. Our aim in this paper, then, is essentially twofold. First, we wish to shed light on the differing implications of the alternative driving forces on our economy's endogenous variables. We shall compare our results to the UK stylized facts, but as we shall show below these are consistent with data from a number of economies. And second, more generally, to analyze the extent to which models based on forward-looking optimizing consumption behavior capture variations in the actual current account.

The paper is structured as follows. Section 2 outlines the stylized facts of the UK economy and the cyclical behavior of the current account across a number of countries. Section 3 develops our dynamic stochastic general equilibrium model driven by either of productivity and preference shocks. Section 4 outlines the calibration techniques used to assesses the fit of these two models. Section 5 concludes and offers some pointers to future work.

\footnotetext{
${ }^{7}$ For example they find that in the pre-war period the price-level is, if anything, slightly pro-cyclical while the real wage is basically acycical. (These correlations hold good whether or not one includes the volatile inter-war years.) In the post-war period the real wage is strongly pro-cyclical, while the price-level is strongly countercyclical.
} 


\section{Some Open Economy Stylized Facts}

This section outlines some of the basic facts on our open economy. There are two main dimensions along which we will try to map the UK economy: (i) the covariation of the main economic indicators with the economic cycle, measured by the business cycle fluctuation in output per head, and (ii) the relative volatility of each series. Table 1 presents the observed data on the business cycle component of the UK economy obtained with the band pass filter recommended by Baxter and King (1999). ${ }^{8}$ Investment and the current account are the most volatile series. Output and consumption display lower and similar levels of volatility. Observed real wages show relatively little cyclical variation and, as suggested by King and Rebelo (1999), the capital stock displays little important variation at the business cycle frequencies. Consumption, investment, real wage and hours supplied are pro-cyclical whilst the current account is countercyclical. Output shows positive leads for consumption, investment and wages while there are negative leads for the current account. The current account and, to some extent, real wages negatively lead output, while consumption, investment and labor supply positively lead output.

It is the countercyclicality of the current account which is striking. Figure 1 explores the cyclicality of the current account from a somewhat longer perspective. We plot the cyclical component of the current account (bold line) against both the cyclical component of output per head (dashed line) and the phases of expansion and contraction and find clear evidence that the current account is countercyclical. By full sample or by sub-sample and across a wide range of business cycle filters the current account appears not only countercyclical (Table 2, Panel A) but also significantly more volatile than output per head in the UK. In Table 2, Panel B we present Razin's (1995) finding that a countercyclical current account seems to be standard across the G7, where only in Japan and France does the current account appear acyclical.

This finding is now considered standard in the literature (Baxter and Crucini (1995)). Standard intertemporal reasoning tells us that a countercyclical current account can result from permanent income shocks. For example, a positive permanent income shock will lead to forward-looking consumers increasing current consumption by the annuity value of that increase and to borrowing from abroad whilst output responds with a lag (Glick and Rogoff (1995)). But if we suspect that agents propensity to consume changes through time (Hall (1997)) we might also argues that any tendency for preferences to move countercyclically will also lead to a countercyclical current account.

In the following section, we move on to build two versions of a DSGE model with either of productivity or preference innovations as the driving processes. As well as concentrating on the ability of these two sets of forcing variables to explain the observed moments of the

\footnotetext{
${ }^{8} \mathrm{~A}$ wider range of series' moments results are available on request as are the results of different filtering procedures. Our programs for implementing the filter we used are also available. A full data annex is also available on request but note all data is sourced from the ONS. All expenditure series are measured in per capita terms.
} 
current account outlined in this section (see Figure 2 for a summary), we will also examine these two models, more generally, in terms of their ability to explain the moments of the main expenditure and factor supply moments.

\section{An Open Economy Model}

Consider the a small open economy which faces an exogenous real interest rate determined, without any impediment, in fully integrated world capital markets. The exogenous real rate raises the following issue: that, unless the interest rate just equals the discount factor, the agent (in our model, the cohort) will be accumulating (if $r>\delta$ ) or decumulating (if $r<\delta$ ) net foreign assets such that we strain the small country assumption. ${ }^{9}$ We address this issue by adopting the approach of Yaari (1965), and assuming that agents in our model face finite lives. In particular we follow Cardia (1991) and adopt a discrete time (open economy) version of Blanchard (1985).

\subsection{The Representative Agent}

The representative agent derives utility from consumption of a single non-durable good, $C_{t}$, and leisure, $L_{t}$. Each period, she faces a constant (i.e., time-independent) probability of death, $\lambda$, which lies in the (open) unit interval. Let $\delta$ denote the subjective discount rate. Equation (1) represents her expected lifetime utility

$$
V_{0}=E_{0} \sum_{t=0}^{\infty}\left(\frac{1}{1+\delta}\right)^{t}\left(\frac{1}{1+\lambda}\right)^{t} u\left(C_{t}, L_{t}\right) .
$$

We make the usual assumptions concerning the differentiability of the utility function, which we also assume is concave and increasing in both its arguments. Her maximization is subject to a sequence of per period budget constraints,

$$
C_{t}+B_{t+1}=(1+r)(1+\lambda) B_{t}+\Pi_{t}+W_{t} N_{t}
$$

and a transversality condition, which we spell out below. ${ }^{10}$ That is, total consumption, $C_{t}$, plus purchases of net foreign assets, $B_{t+1}$, is equal to net income. Net income comprises

\footnotetext{
${ }^{9}$ We are not implying, of course, that the underlying optimization problem is ill-posed since the budget set remains compact, in particular bounded. The point is simply that, for reasonable parameter values, $r \neq \delta$ can imply large steady state net asset holdings. In our discussion of the steady state properties of our model we discuss this point further and compare our steady state net asset position with that of a more conventional representative agent model.

${ }^{10}$ Our formulation of the budget constraint follows, amongst others, Carlstrom and Fuerst (1995). This is convenient since the stock of 'net wealth' can be captured simply by $B_{t}$. This makes calculating the steady state net foreign asset position simple (see below). In addition, it is straightforward to show that our formulation recovers (i.e., is isomorphic to) the optimality conditions of an altermative formulation
} 
net income from foreign assets, $(1+r)(1+\lambda) B_{t}$, profits from the representative firm, $\Pi_{t}$, and labor income, $W_{t} N_{t}$. And labor income in turn equals the product of the per period wage rate and the amount of time spent working. The first-order conditions for an interior optimum will include:

$$
\begin{gathered}
u_{c}^{\prime}\left(C_{t}, L_{t}\right)=\left(\frac{1+r}{1+\delta}\right) E_{t} u_{c}^{\prime}\left(C_{t+1}, L_{t+1}\right) \\
\frac{u_{l}^{\prime}\left(C_{t}, L_{t}\right)}{u_{c}^{\prime}\left(C_{t}, L_{t}\right)}=W_{t} .
\end{gathered}
$$

Equation (3) demonstrates that at the individual (cohort) level, the probability of death entails no tilting of consumption, other than what would normally occur in models with infinitely-lived consumers and a discrepancy between the risk free rate and the subjective discount factor. Consider a net creditor who wishes to secure, in expectation, that her advance returns principal plus the risk free interest rate. To do this she needs to take account of the fact that the borrower may not survive to repay the loan. Assuming a version of the law of large numbers such that the proportion of the population that does survive is given by $(1+\lambda)^{-1}$, then her expected return is given by the product of the proportion of the cohort that survives and the amount repaid, $(1+r)(1+\lambda) B_{t+1} \cdot{ }^{11}$ Equation (4) governs the optimal supply of labor. The situation changes radically with respect to aggregate consumption when we integrate over all currently alive cohorts. First we note that the size of the cohort born each period is given by

$$
\left(\frac{\lambda}{1+\lambda}\right)\left(\frac{1}{1+\lambda}\right)^{t} .
$$

As a result of this effect, the size of the cohort decreases monotonically with time, and the sum of all currently alive cohorts is equal to unity, that is ${ }^{12}$

$$
\frac{\lambda}{1+\lambda} \sum_{j=-\infty}^{t}\left(\frac{1}{1+\lambda}\right)^{(t-j)}=1 \text {. }
$$

To obtain an expression for aggregate consumption we first need to calculate the agent's present value budget constraint. Iterating on (2) in the usual way, we observe that:

which includes capital in the representative agents budget constraint. Doing this, however, complicates the calculation of the model's steady state somewhat. In addition, it is well known that the capital stock varies little over the business cycle, so that including capital in our definition of net wealth adds little to our simulations.

${ }^{11}$ Frankel and Razin (1992).

${ }^{12}$ We outline in more detail in an appendix the construction of our discrete approximation to the continuous exponential density. 


$$
\begin{aligned}
& \sum_{s=t}^{\infty} E_{t}\left[\left(\frac{1}{1+r}\right)^{s-t}\left(\frac{1}{1+\lambda}\right)^{s-t} C_{s}\right] \\
& =(1+r)(1+\lambda) B_{t}+\sum_{s=t}^{\infty} E_{t}\left[\left(\frac{1}{1+r}\right)^{s-t}\left(\frac{1}{1+\lambda}\right)^{s-t}\right]\left[\Pi_{s}+W_{s} N_{s}\right]
\end{aligned}
$$

Again equation (6) is a familiar expression, except that both it and the transversality condition now reflects the probability of death:

$$
E_{t}\left(\frac{1}{1+r}\right)^{T}\left(\frac{1}{1+\lambda}\right)^{T} B_{t+T+1} \rightarrow 0 \quad \text { as } \quad T \rightarrow \infty .
$$

Employing log utility, we note that a simple stochastic difference equation governs consumption dynamics at the individual level, $E_{s} C_{s+1}=[(1+r) /(1+\delta)] C_{s}$. Using this expression in (6) successively to substitute for future consumption, we find that

$$
\begin{aligned}
C_{t} & =\frac{(1+\lambda)(1+\delta)-1}{(1+\lambda)(1+\delta)} \cdot[(1+\lambda)(1+\delta)] B_{t} \\
& \left.+E_{t} \sum_{s=t}^{\infty}\left[\left(\frac{1}{1+r}\right)^{s-t}\left(\frac{1}{1+\lambda}\right)^{s-t}\right]\left[\Pi_{s}+W_{s} N_{s}\right]\right\rangle
\end{aligned}
$$

Ultimately, we can use (8) to derive an expression for aggregate consumption dynamics and this is given in $(9):^{13}$

$$
E_{t} C_{t+1}=\left(\frac{1+r}{1+\delta}\right) C_{t}-\lambda(1+r) \beta \Omega_{t+1},
$$

where $\beta \equiv \frac{(1+\lambda)(1+\delta)-1}{(1+\lambda)(1+\delta)}$. Here we see that any wedge between the subjective discount factor and the market interest rate need not imply inexorable changes in the level of net foreign assets. Equations (2) and (4), in aggregated form, along with (9) are the three key equations from the representative agent portion of the model.

\subsection{The Representative Firm}

We now turn to the problem facing the representative firm. First, we posit that output be characterized by a Cobb-Douglas production function:

$$
Y_{t}=A_{t} K_{t}^{\alpha}\left((1+\gamma)^{t} N_{t}\right)^{1-\alpha}
$$

\footnotetext{
${ }^{13}$ See Appendix II.
} 
where $A_{t}$ is the Solow residual, consisting of a trend and stochastic component. We denote the $\log$ of the stochastic component by $a_{t}$, and we assume that $a_{t}=\rho a_{t-1}+\epsilon_{t}$, with $\epsilon \sim$ i.i.d. $\left(0, \sigma_{\epsilon}^{2}\right)$. A labor-augmenting growth factor is given by $(1+\gamma)$ and the common trend among the real magnitudes in our model, including the Solow residual. $K_{t}$ is the capital stock, and $L_{t}$ is the labor input. Firms maximize total profits (suitably discounted so that aggregate utility is maximized) subject to a capital evolution equation, which says that the evolution of the capital stock is subject to a constant rate of depreciation, $\psi$, and a cost of adjustment $\phi($.$) where \phi$ is strictly concave, increasing in investment, $I_{t}$, and decreasing in the (predetermined) capital stock. That is, where

$$
K_{t+1}=(1-\psi) K_{t}+\phi\left(\frac{I_{t}}{K_{t}}\right) K_{t}
$$

Formally, the firm faces the following maximand:

$$
\begin{aligned}
J_{t} & =E_{0} \sum_{t=0}^{\infty}\left(\frac{1}{1+\delta}\right)^{t} \mu_{t}\left\{A_{t} K_{t}^{\alpha}\left[(1+\gamma)^{t} N_{t}\right]^{1-\alpha}-W_{t} N_{t}-I_{t}\right\} \\
& +E_{0} \sum_{t=0}^{\infty}\left(\frac{1}{1+\delta}\right)^{t} \Lambda_{t}\left\{\phi\left(\frac{I_{t}}{K_{t}}\right) K_{t}+(1-\psi) K_{t}+K_{t+1}\right\} .
\end{aligned}
$$

Where $\mu_{t}$ is the marginal utility of aggregate consumption and $\Lambda_{t}$ is an undetermined multiplier. ${ }^{14}$ The optimality conditions are given by equations (11), (13) and (14):

$$
\begin{gathered}
\Lambda_{t} \phi\left(I_{t} / K_{t}\right)=\mu_{t} \\
\Lambda_{t}=E_{t}\left\{\alpha\left(\frac{1}{1+\delta}\right) \mu_{t+1} A_{t+1} K_{t}^{\alpha-1} N_{t+1}^{1-\alpha}\right\} \\
+E_{t} \Lambda_{t+1}\left[\phi\left(\frac{I_{t+1}}{K_{t+1}}\right)-\phi\left(\frac{I_{t+1}}{K_{t+1}}\right) \frac{I_{t+1}}{K_{t+1}}+(1-\psi)\right] .
\end{gathered}
$$

The preceding two equations are basically a $q$-model of investment. ${ }^{15}$ But unlike earlier formulations our optimality equations, (11), (13) and (14), will allow us to track the effects of stochastic variation in the marginal utility of consumption. The Cobb-Douglas production function, equation (10), also yields the following expressions for the marginal product of labor and capital, and these are given, respectively, by equations (15) and (16):

$$
W_{t}=(1-\alpha) A_{t} K_{t}^{\alpha}\left[(1+\gamma)^{t} N_{t}\right]^{-\alpha}(1+\gamma)^{t}
$$

\footnotetext{
${ }^{14}$ Note that as the marginal utility of consumption across cohorts is equal aggregation is straightforward.

${ }^{15}$ This set-up echoes that of King and Watson (1996).
} 


$$
Z_{t}=\alpha A_{t} K_{t}^{\alpha-1}\left[(1+\gamma)^{t} N_{t}\right]^{1-\alpha} .
$$

Two additional equations, or adding-up constraints, complete the description of our model economy. First, there is the fundamental time endowment operating on the representative agent such that the total time available in any period for leisure and labor is normalized to unity.

$$
N_{t}+L_{t}=1
$$

The economy also faces a resource constraint which determines the evolution of net foreign assets. This is given in equation (18):

$$
B_{t+1}-B_{t}=r B_{t}+Y_{t}-C_{t}-I_{t}
$$

Equations (17-18) complete the description of the economy. Under standard restrictions that ensure both the feasibility and desirability of a steady-state growth path we are able to transform the growth model and work with its stationary form by dividing all the growth variables by the common growth factor. So, for example, we employ the following form of the variables, $C_{t} \equiv C_{t} /(1+\gamma)^{t}$ and $K_{t+1} \equiv(1+\gamma) K_{t+1} /(1+\gamma)^{t+1} .{ }^{16}$

\subsection{The Linearized Model}

In what follows time sub-scripted lower case letters refer to percentage deviations from steady state of our model equations in stationary form and lower case letters with no subscripts refer to steady state values, for example, $c_{t} \equiv d C_{t} / c$ where $C_{t} \equiv C_{t} /(1+\gamma)^{t}$ and $c$ is the steady state value of consumption. So, our final model equations are given by (19)-(28):

$$
\begin{gathered}
(1+\gamma) E_{t} c_{t+1}=\left(\frac{1+r}{1+\delta}\right) c_{t}-\lambda(1+r)(1+\gamma) \beta(b / c) b_{t+1} \\
y_{t}=(c / y) c_{t}+(i / y) i_{t}-(1+r)(b / y) b_{t}+(1+\gamma)(b / y) b_{t+1} \\
(c / l) c_{t}-(c / l) l_{t}=\frac{\theta w}{1-\theta} w_{t},
\end{gathered}
$$

\footnotetext{
${ }^{16}$ See, for example, the discussion on pp. 944-5 in King and Rebelo (1999).
} 


$$
n n_{t}+l l_{t}=0
$$

$$
(1+\gamma) k_{t+1}=(1-\psi) k_{t}+(i / k) i_{t}
$$

$$
\frac{(i / k)}{(1+\delta) \zeta} E_{t}\left(i_{t+1}-k_{t+1}\right)+\frac{r+\psi}{1+\delta} E_{t}\left(c_{t+1}-z_{t+1}\right)-\left(\frac{1-\psi}{1+\delta}\right) E_{t} \lambda_{t+1}=-(1+\gamma) \lambda_{t}
$$

$$
\begin{gathered}
y_{t}=\alpha k_{t}+(1-\alpha) n_{t}+a_{t}, \\
w_{t}=\alpha\left(k_{t}-n_{t}\right)+a_{t}, \\
z_{t}=(\alpha-1)\left(k_{t}-n_{t}\right)+a_{t}, \\
i_{t}=-\zeta\left(c_{t}+\lambda_{t}\right)+k_{t},
\end{gathered}
$$

where $\zeta \equiv \frac{\phi^{\prime}(.)}{\frac{i}{k} \cdot \phi^{\prime \prime}(.)}$ and corresponds to the slope of the investment demand function. Hence we have 10 endogenous variables, two of which are pre-determined, $b_{t+1}$ and $k_{t+1}$ such that $E_{t} b_{t+1}=b_{t+1}$, and $E_{t} k_{t+1}=k_{t+1}$. The model has two stable roots that can be associated with the two pre-determined variables, and otherwise meets the Blanchard-Kahn criteria for a unique bounded rational expectations solution.

\subsection{The Model Driven by Preference Shocks}

We construct our model driven by preference shocks in the following way. The per period utility function is given by,

$$
U_{t}=\theta X_{t} \ln C_{t}+\left(1-\theta X_{t}\right) L_{t}
$$

where $X_{t}$ denotes the "shock" to preferences in period $t$. The optimization problem basically proceeds as above, with marginal utility being shocked each period in the manner 
indicated. ${ }^{17}$ In addition to altering the labor-leisure trade-off from what obtains in our previous model, this 'stochastic' marginal utility also impacts on the evolution of aggregate consumption and on decisions of the corporate sector. To see this, note that the marginal utility of consumption is now given by:

$$
\left(\frac{1}{1+\lambda}\right)^{t} \frac{X_{t} \theta}{C_{t}}=\mu_{t}
$$

and the labor-leisure trade-off is given by:

$$
\frac{1-\theta X_{t}}{\theta X_{t}} \frac{C_{t}}{L_{t}}=W_{t}
$$

Recall that the first order expression for consumption in the productivity shock model was standard: $E_{s} C_{s+1}=[(1+r) /(1+\delta)] C_{s}$. But in this model the expression becomes $E_{s} C_{s+1}=\left(X_{s+1} / X_{s}\right)[(1+r) /(1+\delta)] C_{s}$. Following the procedures described above (and in the Appendix) aggregate consumption dynamics are described by the following equation,

$$
(1+\gamma) E_{t} C_{t+1}=\frac{1+r}{1+\delta} C_{t}-\lambda(1+r)(1+\gamma) \beta B_{t+1}
$$

where $\beta$ is now given by

$$
\beta \equiv \frac{(1+\lambda)(1+\gamma)-\nu}{(1+\lambda)(1+\gamma)}
$$

Here $\nu$ corresponds to the persistence parameter on the $\mathrm{AR}(1)$ process governing the evolution of the taste shock. Following the notational convention adopted above with respect to the Solow residual, we may write $x_{t+1}=\nu x_{t}+u_{t}$, where $u \sim$ i.i.d. $\left(0, \sigma_{u}^{2}\right)$, where $x$ denotes the detrended log preference shock. The optimality conditions governing the shadow price of capital and investment are then found as above using the logapproximation of (30).

Apart from (19') the other revised linear equations are :

$$
(c / l) c_{t}-(c / l) l_{t}=\frac{w \theta}{1-\theta} w_{t}+\frac{\theta}{1-\theta}\left(\frac{l w+(1-\theta) c}{l}\right) x_{t},
$$

\footnotetext{
${ }^{17}$ Strictly speaking we should spell out the conditions on the support of $X$ such that the utility function remains continuous in its domain. We sidestep these somewhat technical issues here and assume that the relevant regularity conditions are met.
} 


$$
\begin{gathered}
\lambda_{t}(1+\gamma)=\frac{r+\psi}{1+\delta} E_{t}\left(x_{t+1}-c_{t+1}+z_{t+1}\right)+ \\
\frac{1-\psi}{r+\delta} E_{t} \lambda_{t+1}-\frac{(i / k) \zeta^{-1}}{1+\delta} E_{t}\left(i_{t+1}-k_{t+1}\right), \\
i_{t}=\zeta\left(x_{t}-c_{t}-\lambda_{t}\right)+k_{t} .
\end{gathered}
$$

Note that the shock in period $t$ reduces the demand for investment in the current period, while at the same time increasing the desirability of having a higher capital stock in future periods. Finally, note that the preference shock model is approximated by same set of equations (19)-(28) as for the productivity shock model. ${ }^{18}$

\section{Calibration and Solution}

We discuss only briefly the calibration of our models. ${ }^{19}$ We adopt standard parameter values for our model. Table 3 lists the fundamental parameters and we explain the derivation of the other steady values. The annual probability of death, $\lambda$, is taken to be $1 / 67$ and for quarterly data this translates into the $0.373 \%$. The quarterly real return on capital, $r$, in an industrialized economy such as the UK is taken to be $1.25 \%$. The share of capital, $\alpha$, in the production function is taken to $38 \%$. We assume, following King and Rebelo (1999) that the quarterly rate of capital depreciation, $\psi$, is $2.5 \%$. Per capita income growth, $\gamma$, in the UK is $0.5 \%$. And the quarterly rate of time preference is assumed to be around the level implied by market real interest rates, $0.75 \%$. We explain the remaining parameters, $\beta, b, c, y, i, l, N, L$ and $\theta$ in turn. In steady-state we have:

$$
z=r+\psi=\alpha\left(\frac{K}{N}\right)^{\alpha-1},
$$

where we have used the steady state analogues of equations (11), (13) and (14). We solve for $K / N$ and find 41.9. From (24) we note that $Y / N=K / N^{\alpha}=4.135$ and thus $K / Y=10.133$. From $(22) i / k=\gamma+\psi$ and $i / y=(\gamma+\psi) k / y$ that is 10.13 and 0.304 , respectively. Now note:

$$
w_{t}=(1-\alpha)\left(\frac{K}{N}\right)^{\alpha}
$$

\footnotetext{
${ }^{18}$ But, of course, with $a_{t}=0, \forall_{t}$. Naturally $19 ', 21 ', 24$ ' and 28 ' replace the equations in 3.3.

${ }^{19}$ A spreadsheet calculating all our parameter values and steady state values (including extensive sensitivity calculations) is available on request.
} 
and so equals 0.513. We shall assume that we spend a fifth our time working and so $N / L=0.25$ and so $y, k$ and $i$ equal $0.827,8.379$ and 0.251 , respectively. We now solve for $b$ and $c$ simultaneously using (18) and the current account identity:

$$
y-c-i=(\gamma-r) b
$$

to give us -0.501 and 0.571 , respectively. Finally, $\theta$, is given by the intratemporal efficiency condition (20) and is found to be 0.535 .

The model is then specified as a singular linear difference model under rational expectations with two alternate driving processes. The solution specifies the vector of endogenous variables as a function of predetermined variables and on the exogenous driving processes. And the predetermined variables are expressed as functions of their state in the preceding time period and the previous period's driving processes. This recursive solution allows us to generate a fully specified artificial economy for which we can analyze and compare moments to the observed open economy business cycle. ${ }^{20} \mathrm{We}$ construct the empirical measures of the driving processes in an entirely standard way. The Solow residual is easily calculated given empirical measures of the capital stock and labour input. Similarly, using equation (21'), we can calculate a measure of the preference shock given a measure of labour input, labour income and consumption. In practice the preference shock turns out to be about as persistent as the TFP shock, but somewhat more volatile. ${ }^{21}$

\section{Results}

Figures 3 and 4 show the impulse responses of output, consumption, investment and real wages to each of the productivity and preference shocks, respectively. We note immediately that both models deliver a reasonable and immediate output response to either shock and, in each case, a smooth consumption response. Note though that the jump in consumption is proportionally greater in the case of the productivity model. Similarly investment exhibits a substantially more elastic response to the productivity shock than the preference shock - together the responses of the two expenditure components suggest that foreign assets will be accumulated (decumulated) with the model driven by the productivity (preference) shock. Finally, note the opposing responses of real wages under the two models.

The main results of the calibrated model are presented in Tables 4 and 5, as direct analogues of Table 2 on the observed data, and in Figures 5 and 6 as analogues of Figure 2. Figures 7 and 8 compare the band pass filtered generated series on the

\footnotetext{
${ }^{20}$ Full solution results, including Markov decision rules, are available on request. See King and Watson (1995) for a fuller description of the method used.

${ }^{21} \mathrm{In}$ particular, $\sigma_{P R E F}=4.79 \%(\rho=0.9)$ while $\sigma_{T F P}=2.06 \%(\rho=0.95)$.
} 
main expenditure components to the observed UK data. The results in Table 4, from the model driven by productivity shocks, are familiar from the dynamic stochastic general equilibrium literature, although recall that we are here working in an overlapping generations framework. This model basically ranks variables, in terms of their standard deviations, in a manner consistent with the data (although notably it exaggerates the smoothness of consumption). In terms of the contemporaneous correlations with output per head, all our results are consistent with the data, although the degree of these correlations is high. We note, in particular, that the productivity driven model captures both the fact that the current account is a relatively volatile variable and that it is strongly countercyclical. The striking aspect of this result is the extent to which the artificial data captures the dynamic, as well as contemporaneous, correlations of the observed data (Figure 3) - positive leads for consumption, investment, hours worked, real wages and the capital stock and negative leads for the current account.

The results in Table 5 and Figures 6 and 8 are for the model driven by preference shocks. Overall, the fit seems less impressive, both contemporaneously and in the dynamics. There are a number of striking failures. First, output appears somewhat more volatile than in the data, although more worrying is the lack of variability in the generated investment and current account data. The model also generates counterfactually signed contemporaneous correlations between wages and output and crucially between the current account and output. The failure of the preference shock driven model to track the current account is partly related to the lack of variability in the investment series. A positive shock raises the desirability of consumption and acts as a negative shock to the capital-labor ratio, driving real wages down. Since these shocks are highly correlated (in our data the autocorrelation coefficient is 0.95 ), that certainly raises the desirability increasing the future capital stock. However, the same shock reduces the attraction of investment in the current period. To a first-order approximation, these effects appear to be largely offsetting, resulting in a relatively 'flat' investment series. The source of these offsetting effects are apparent on visual inspection of equations (24') and (28'). This lack of response of investment and the smooth profile for consumption coupled with the large rise in output following a positive preference shock (the latter driven by high labor elasticities) result in a strongly pro-cyclical and counterfactual current account series.

The results presented in this section suggest that a model driven by productivity innovations is preferable to one relying on preference shifts as the explanation of the second moments of aggregate data, the dynamics of the business cycle and, perhaps most importantly, the countercyclicality of the current account. Put alternatively, the employment of a driving process defined by productivity innovations has been able to provide a plausible explanation of the external balance within the context of a sparse general equilibrium model. On the evidence provided by the UK economy it seems to us that an equally sparse model relying on preference shifts seems less well placed to explain 
the cyclical fluctuations in the current account. ${ }^{22}$ In addition, Chadha and Nolan (2001) find that these results are robust to important extensions to the basic model (such as variable capacity utilization).

\section{Concluding Remarks}

It may well be that at least some stylized business cycle facts come and go. That was partly the conclusion of some recent work on the UK business cycle, Chadha, Janssen and Nolan (2000). However some facts are more enduring (through time and across countries), such as the countercyclicality of the current account, and it seems important to construct models that track these 'robust' facts. In this paper we have examined whether two stochastic processes - thought to be at the root of many, if not most, business cycles helped simple versions of a stochastic growth model to track some of these robust stylized facts. We found that a model driven by preference shocks generated a number of striking counterfactual results, and hence that the model driven by productivity shocks offered important advantages.

At least two related issues appear important for future work. The (highly persistent) productivity shift term has been shown to fend off the preference shift term but works the economy too hard in a number of dimensions. Measured productivity seems to be responsible for most of the internally generated propagation within this model ${ }^{23}$ but also leads, inter alia, to a counterfactually responsive labor market in terms of both hours supplied and its relative price. Allowing more persistent responses of macroeconomic aggregates along with a more lumpy labor market may require two modifications to our baseline model. Some consideration of the question of heterogeneity of cohorts through time may allow a more realistic treatment of consumption dynamics, that is, with greater persistence and volatility. And the introduction of costs to labor employment may lead to greater hump backed response of outputs without a highly persistent series of shocks (Walsh (2000)). Correcting the modeling of the open economy for internal market imperfections represents an important next stage of this research effort.

\footnotetext{
${ }^{22}$ It seems possible to consider that small open economies with pro-cyclical current acounts, countercyclical real wages and pro-cyclical capital stocks may be ones where preference shocks dominate.

${ }^{23}$ As in more standard infinitely lived representative agent models.
} 
Table 1. Observed Data - Summary UK facts

$\begin{array}{ccccccccccc}\text { Variable } & \sigma & y_{t-4} & y_{t-3} & y_{t-2} & y_{t-1} & y_{t} & y_{t+1} & y_{t+2} & y_{t+3} & y_{t+4} \\ y & 1.59 & & & & & & & & & \\ c & 1.52 & 0.491 & 0.598 & 0.706 & 0.785 & 0.805 & 0.749 & 0.624 & 0.459 & 0.284 \\ i & 3.76 & 0.430 & 0.563 & 0.671 & 0.736 & 0.744 & 0.690 & 0.585 & 0.453 & 0.315 \\ w & 0.91 & 0.310 & 0.220 & 0.182 & 0.177 & 0.163 & 0.108 & 0.013 & -0.093 & -0.179 \\ c a & 3.83 & -0.385 & -0.469 & -0.532 & -0.565 & -0.561 & -0.513 & -0.414 & -0.272 & -0.113 \\ n & 1.67 & 0.520 & 0.646 & 0.769 & 0.840 & 0.817 & 0.691 & 0.491 & 0.270 & 0.075 \\ k & 0.10 & 0.180 & 0.119 & 0.063 & 0.017 & -0.014 & -0.034 & -0.044 & -0.056 & -0.075\end{array}$

Notes: For Tables 1, 3 and 4 the presented moments refer to the band pass filtered data with 12 quarters' weights, see Baxter and King (1999) for further details. The full sample for all data is 1963:1 to 1998:4.

Table 2. Current Account and the Cycle

Panel A:

\begin{tabular}{ccccccc} 
Annual & \multicolumn{2}{c}{ Baxter-King } & \multicolumn{2}{c}{ Christiano-Fitzgerald } & \multicolumn{2}{c}{ Hodrick-Prescott } \\
& Full & Postwar & Full & Postwar & Full & Postwar \\
Corr.(y,ca) & -0.24 & -0.64 & -0.17 & -0.54 & -0.31 & -0.57 \\
s.d.(y) & 2.23 & 1.41 & 2.18 & 2.05 & 2.43 & 2.10 \\
s.d. (ca) & 8.92 & 9.09 & 8.70 & 8.80 & 8.85 & 8.90
\end{tabular}

Panel B:

$\begin{array}{cccc} & \text { s.d. of } \mathbf{y} & \text { s.d. of T.B } & \text { Corr }(\mathbf{T . B .}, \mathbf{Y}) \\ \text { US } & 2.17 & 9.00 & -0.277 \\ \text { UK } & 1.98 & 7.98 & -0.538 \\ \text { France } & 1.49 & 4.59 & -0.019 \\ \text { Germany } & 1.92 & 6.19 & -0.299 \\ \text { Italy } & 2.17 & 10.20 & -0.210 \\ \text { Canada } & 2.01 & 5.37 & -0.709 \\ \text { Japan } & 3.58 & 13.48 & 0.054\end{array}$

Notes: y denotes GDP, ca the current account balance, TB the trade balance, s.d., the standard deviation in percentage terms, and Corr the correlation coefficient. Results for Panel A, from Chadha et al (2000), refer to an annual UK study over the period 1871-1997 and to three different filtering procedures. Results for Panel B are at the annual frequency, from Razin (1995), in which the original source is IFS and cover the period 1960 to 1989 . 
Table 3. Quarterly percentages

$\begin{array}{llllll}\lambda & r & \alpha & \psi & \gamma & \delta \\ 0.373 & 1.25 & 38 & 2.5 & 0.5 & 0.75\end{array}$

Table 4. Model Output - Productivity Shock

$\begin{array}{ccccccccccc}\text { Variable } & \sigma & y_{t-4} & y_{t-3} & y_{t-2} & y_{t-1} & y_{t} & y_{t+1} & y_{t+2} & y_{t+3} & y_{t+4} \\ y & 1.59 & & & & & & & & & \\ c & 0.45 & 0.120 & 0.336 & 0.592 & 0.824 & 0.960 & 0.940 & 0.801 & 0.605 & 0.416 \\ i & 7.28 & -0.152 & 0.072 & 0.354 & 0.632 & 0.829 & 0.877 & 0.798 & 0.651 & 0.499 \\ w & 0.78 & 0.237 & 0.445 & 0.679 & 0.882 & 0.990 & 0.944 & 0.791 & 0.589 & 0.396 \\ c a & 6.40 & 0.271 & 0.051 & -0.237 & -0.529 & -0.747 & -0.819 & -0.765 & -0.637 & -0.50 \\ n & 0.82 & 0.478 & 0.652 & 0.827 & 0.955 & 0.990 & 0.896 & 0.720 & 0.515 & 0.327 \\ k & 0.99 & 0.879 & 0.889 & 0.837 & 0.719 & 0.552 & 0.355 & 0.174 & 0.025 & -0.092\end{array}$

Table 5. Model Output - Preference Shock

$\begin{array}{ccccccccccc}\text { Variable } & \sigma & y_{t-4} & y_{t-3} & y_{t-2} & y_{t-1} & y_{t} & y_{t+1} & y_{t+2} & y_{t+3} & y_{t+4} \\ y & 2.90 & & & & & & & & & \\ c & 0.77 & 0.530 & 0.698 & 0.856 & 0.956 & 0.959 & 0.844 & 0.644 & 0.410 & 0.189 \\ i & 0.91 & -0.239 & -0.010 & 0.263 & 0.530 & 0.734 & 0.829 & 0.822 & 0.748 & 0.648 \\ w & 1.72 & -0.343 & -0.551 & -0.764 & -0.930 & -0.999 & -0.943 & -0.789 & -0.584 & -0.381 \\ c a & 1.54 & 0.496 & 0.656 & 0.845 & 0.961 & 0.985 & 0.898 & 0.727 & 0.518 & 0.315 \\ n & 4.62 & 0.361 & 0.566 & 0.775 & 0.935 & 1.00 & 0.940 & 0.784 & 0.579 & 0.376 \\ k & 0.14 & 0.801 & 0.829 & 0.804 & 0.723 & 0.598 & 0.448 & 0.295 & 0.153 & 0.026\end{array}$




\section{References}

[1] Backus, D K, P J Kehoe and F E Kydland (1994) "Dynamics of the Trade Balance and the Terms of Trade: The J-Curve?", American Economic Review, 84, pp.84-103.

[2] Baxter M (1995) "International Trade and Business Cycles", in Gene M Grossman and Kenneth Rogoff (Eds), Handbook of International Economics, Volume 3, Amsterdam: Holland.

[3] Baxter M and M J Crucini (1995) "Business Cycles and the Asset Structure of Foreign Trade", International Economic Review, 36, pp.821-54.

[4] Baxter M and R G King (1999) "Approximate Bandpass Filters for Economic Time Series", Review of Economics and Statistics, 81, pp.575-93.

[5] Blanchard O J and C Kahn (1980) "The Solution of Linear Difference Models Under Rational Expectations" Econometrica, 48, pp.1305-12.

[6] Blanchard O J (1985) "Debts, Deficits and Finite Horizons" Journal of Political Economy, 93, pp.223-247.

[7] Campbell, J Y (1987) "Does Saving Anticipate Declining Labor Income: An Alternative Test of the Permanent Income Hypothesis", Econometrica 55 (Nov) pp.1249-73.

[8] Cardia, E. (1991) "The Dynamics of a Small Open Economy in response to Monetary, Fiscal and Productivity Shocks", Journal of Monetary Economics, 28(3), pp.411-434.

[9] Carlstrom, C.T. and T. S. Fuerst (1995) "Interest Rate Rules versus Money Growth Rules. A Welfare Comparison in Cash-In-Advance Economy", Journal of Monetary Economics, 36, pp.247-267.

[10] Chadha, J S, N Janssen, and C Nolan (2000) "An Examination of UK Business Cycle Fluctuations: 1871-1997", University of Cambridge, Department of Applied Economics Working Paper 0024.

[11] Chadha, J S and C Nolan (2001) "Supply Shocks and the 'Natural Rate of Interest': An Exploration", University of Cambridge, Department of Applied Economics Working Paper 0103.

[12] Frenkel, J A, and A Razin, (1992) Fiscal Policies and the World Economy, 2nd Edition, Cambridge, MA: MIT Press.

[13] Glick R and K Rogoff (1995) "Global versus Country Specific Productivity Shocks and the Current Account", Journal of Monetary Economics, 35, pp.159-92. 
[14] Hall R (1997) "Macroeconomic Fluctuations and the Allocation of Time", Journal of Labor Economics, 15(1), Part 2, pp.S223-50.

[15] King R G and S Rebelo (1999) "Resuscitating Real Business Cycles", Chapter in M Woodford and J B Taylor (Eds) Handbook of Macroeconomics, Amsterdam: Holland.

[16] King R G and M Watson (1995) "Systems Reduction and Solution Algorithms for Singular Linear Difference Systems Under Rational Expectations", Working Paper, University of Virginia.

[17] King R G and M Watson (1996) "Money, Prices, Interest Rates and the Business Cycle", Review of Economics and Statistics, 78(1), pp.35-53.

[18] Kydland, F E and E C Prescott (1982) "Time to Build and Aggregate Fluctuations", Econometrica, 50, pp.1345-70.

[19] Long, J B and C I Plosser (1983) "Real Business Cycles", Journal of Political Economy, 91, pp.39-69.

[20] Obstfeld M and K Rogoff (1995) "The Intertemporal Approach to the Current Account", in Gene M Grossman and Kenneth Rogoff (Eds), Handbook of International Economics, Volume 3, Amsterdam: Holland.

[21] Obstfeld M and K Rogoff (1996) Foundations of Open Economy Macroeconomics, Cambridge, MA: MIT Press.

[22] Razin, A (1995) "The Dynamic-Optimizing Approach to the Current Account: Theory and Evidence", Chapter 5 in Peter B Kenen (Ed) Understanding Interdependence, Princeton University Press: Princeton.

[23] Walsh, C (2000) "Job Destruction and Monetary Policy", UCSC mimeo.

[24] Woodford, M (2001) "Inflation Stabilization and Welfare", NBER working paper no. 8071.

[25] Yaari, M E (1965) "Uncertain Lifetime, Life Insurance, and the Theory of the Consumer", Review of Economic Studies, 32 (April), pp.137-50. 


\section{Appendix}

\section{Exponential and Discrete Density Functions}

Here we informally show how the exponential density can be approximated by the discrete density we use in the paper. The exponential density is given by (37)

$$
f(\lambda)=\int_{0}^{\infty} \lambda e^{-\lambda t} d t
$$

where $\lambda$ is the constant probability of death, as in Blanchard (1985), and $\frac{1}{\lambda}$ is the expected value of remaining life. That is, the expected value of a random variable is given by

$$
E(x)=\int x f(x) d x
$$

which in the case of the exponential density just becomes

$$
E(.)=\int_{0}^{\infty} t p e^{-p t} d t
$$

Integrating (39) by parts yields

$$
\left.E(.)=-t e^{-\lambda t}\right]_{0}^{\infty}+\int_{0}^{\infty} e^{-\lambda t} d t=\frac{1}{\lambda}
$$

Now, to translate this continuous density to its discrete time analogue note that:

$$
e^{-\lambda t} \simeq\left(\frac{1}{1+\lambda}\right)^{t}
$$

The exponential density is pre-multiplied by $\lambda$, however in discrete time the above factor is not pre-multiplied by $\frac{1}{1+\lambda}$ as one might initially suppose. Note that $\lambda$ is the (negative) of the instantaneous growth rate of the function $e^{-\lambda t}$, so that the discrete time analogue is simply

$$
\frac{\left(\frac{1}{1+\lambda}\right)^{t}-\left(\frac{1}{1+\lambda}\right)^{t-1}}{\left(\frac{1}{1+\lambda}\right)^{t-1}}=\left(\frac{\lambda}{1+\lambda}\right)
$$

Intuitively this ensures that at each point the probability of death is constant: 


$$
\sum_{t=0}^{\infty}\left(\frac{\lambda}{1+\lambda}\right)\left(\frac{1}{1+\lambda}\right)^{t}
$$

The expected value of this distribution is then derived as follows

$$
E(.)=\left(\frac{\lambda}{1+\lambda}\right) \sum_{t=0}^{\infty} t\left(\frac{1}{1+\lambda}\right)^{t}
$$

Focussing on the terms to be integrated, we see that the sum, $S$, is given by

$$
S=0+\left(\frac{1}{1+\lambda}\right)+2\left(\frac{1}{1+\lambda}\right)^{2}+3\left(\frac{1}{1+\lambda}\right)^{3}+\ldots+n\left(\frac{1}{1+\lambda}\right)^{n}
$$

Similarly,

$$
\left(\frac{1}{1+\lambda}\right) S=\left(\frac{1}{1+\lambda}\right)^{2}+2\left(\frac{1}{1+\lambda}\right)^{3}+\ldots+n\left(\frac{1}{1+\lambda}\right)^{n+1}
$$

It then follows that

$$
\begin{aligned}
\left(\frac{\lambda}{1+\lambda}\right) S=\left(\left(\frac{1}{1+\lambda}\right)+\left(\frac{1}{1+\lambda}\right)^{2}+\left(\frac{1}{1+\lambda}\right)^{3}+\ldots+\left(\frac{1}{1+\lambda}\right)^{n}\right) & \\
& -n\left(\frac{1}{1+\lambda}\right)^{n+1}
\end{aligned}
$$

Simplifying this expression and evaluating the sum as $n \rightarrow \infty$, gives that

$$
S=\frac{\left(\frac{1}{1+\lambda}\right)}{\left(\frac{\lambda}{1+\lambda}\right)^{2}}
$$

Using this in expression (44) confirms that expected remaining life is constant and equal to $\lambda^{-1}$.

\section{Calculating Aggregate Consumption}

Whenever a given variable, say the marginal utility of consumption, is constant across cohorts, aggregation, using equation (5) in the main text is straightforward. Here we show how to calculate aggregate consumption dynamics (aggregating equation (4) by comparison is straightforward). From the text we have that 


$$
\begin{aligned}
& C_{t}=\frac{(1+\lambda)(1+\delta)-1}{(1+\lambda)(1+\delta)}\{(1+\lambda)(1+\delta) B_{t}+ \\
&\left.E_{t} \sum_{s=t}^{\infty}\left[\left(\frac{1}{1+r}\right)^{s-t}\left(\frac{1}{1+\lambda}\right)^{s-t}\right]\left[\Pi_{s}+W_{s} N_{s}\right]\right\}
\end{aligned}
$$

Leading this expression one period and subtracting (51) gives:

$$
\begin{aligned}
E_{t} C_{t+1}-C_{t}=\beta\left[(1+r) B_{t+1}+E_{t} \sum_{s=t+1}^{\infty}\right. & \left.\left(\frac{1}{1+r} \frac{1}{1+\lambda}\right)^{s-(t+1)}\left[\Pi_{s}+W_{s} N_{s}\right]\right] \\
& -\beta\left[E_{t} \sum_{s=t}^{\infty}\left(\frac{1}{1+r} \frac{1}{1+\lambda}\right)^{s-t}\left[\Pi_{s}+W_{s} N_{s}\right]\right]
\end{aligned}
$$

Here we have used the aggregate version of the budget constraint, which in effect means dropping the $(1+\lambda)$ factor. This disappears in the aggregate since there can be no net transfer of wealth. We have also assumed that labor productivity is constant across cohorts, so that labor income in the above expression is also aggregate labor income. After some simplification we have that,

$$
\begin{aligned}
& E_{t} C_{t+1}-C_{t}= \\
& \quad-\beta\left(\Pi_{t}+W_{t} N_{t}\right)+\phi \beta\left[E_{t} \sum_{s=t+1}^{\infty}\left(\frac{1}{1+r} \frac{1}{1+\lambda}\right)^{s-(t+1)}\left[\Pi_{s}+W_{s} N_{s}\right]\right] \\
& +\beta\left(r B_{t+1}+Y_{t}-C_{t}\right)
\end{aligned}
$$

where we have used the economy wide resource constraint to substitute out for $B_{t}$, and where $\phi \equiv \frac{(1+\lambda)(1+r)-1}{(1+\lambda)(1+r)}$. Cancelling, and rearranging terms yields

$$
\begin{aligned}
& E_{t} C_{t+1}-\frac{1}{(1+\lambda)(1+r)} C_{t}= \\
& \phi \beta\left[E_{t} \sum_{s=t+1}^{\infty}\left(\frac{1}{1+r} \frac{1}{1+\lambda}\right)^{s-(t+1)}\left[\Pi_{s}+W_{s} N_{s}\right]\right]+\beta r B_{t+1}
\end{aligned}
$$

Now, recall the expression derived in the body of the text for consumption, whereupon we may write the preceding expression as

$$
E_{t} C_{t+1}-\frac{1}{(1+\lambda)(1+r)} C_{t}=\phi C_{t}-\phi(1+r) \beta B_{t+1}+r B_{t+1}
$$

Straightforward simplification of this expression delivers equation (8) in the main text. 
Figure 1 - The UK current account

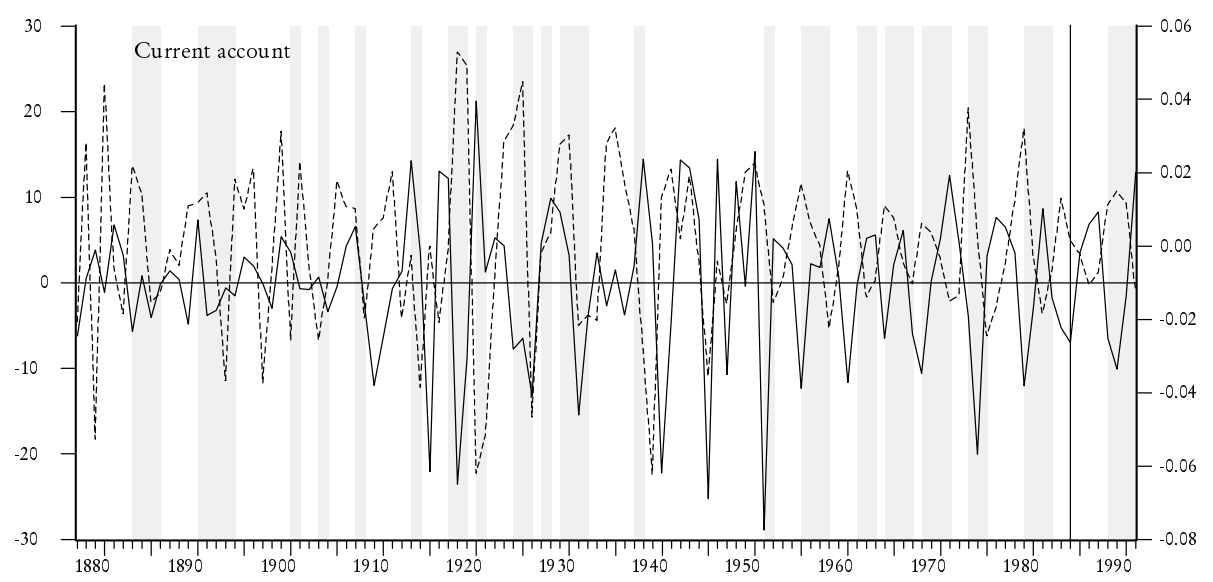

Source - Chadha, Janssen and Nolan (2000). The data are presented following the application of the bandpass filter. The period of dark shading represent periods of downturn i.e. from peak to trough and light shading represent periods from trough to peak.

Figure 1: 


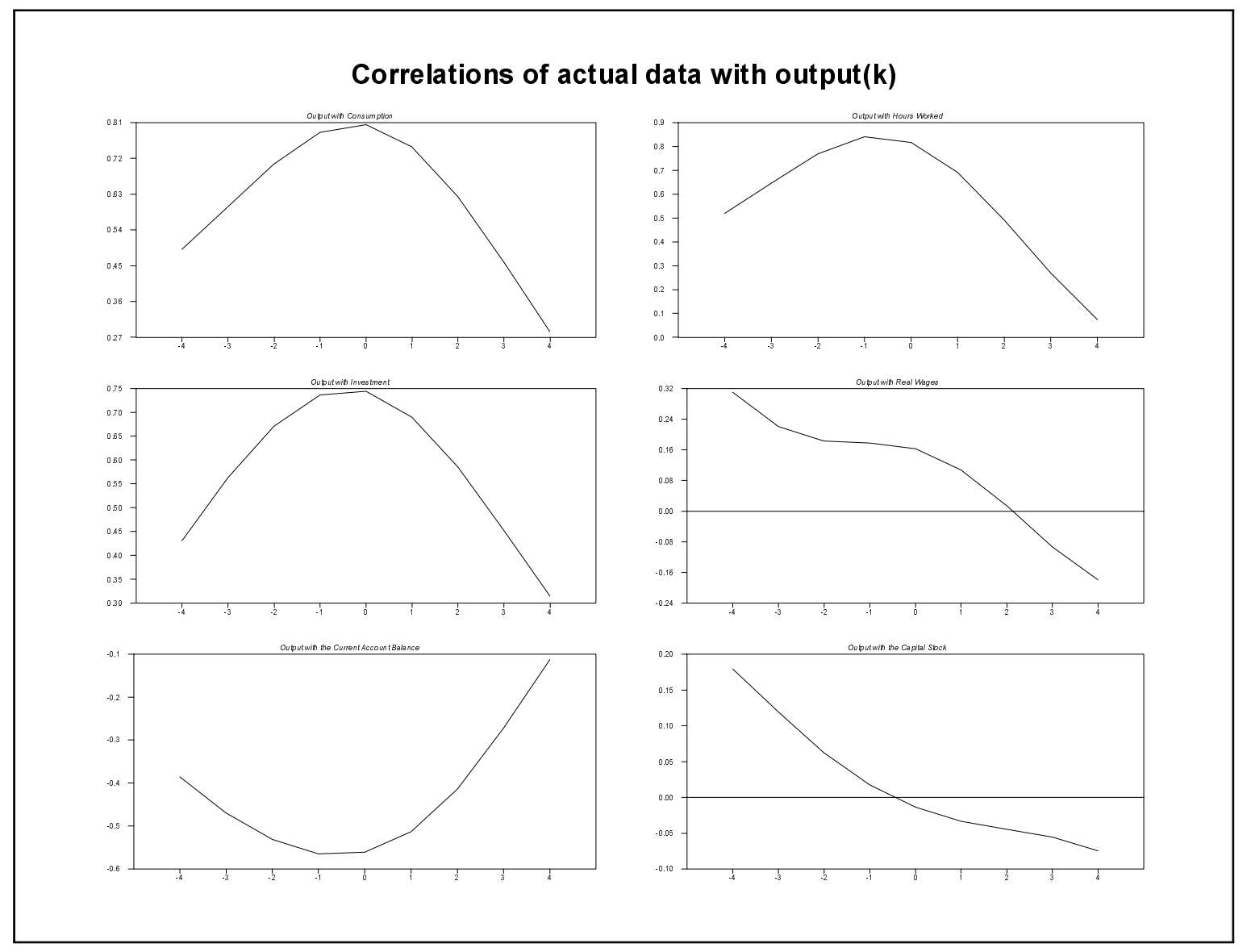

Figure 2: 

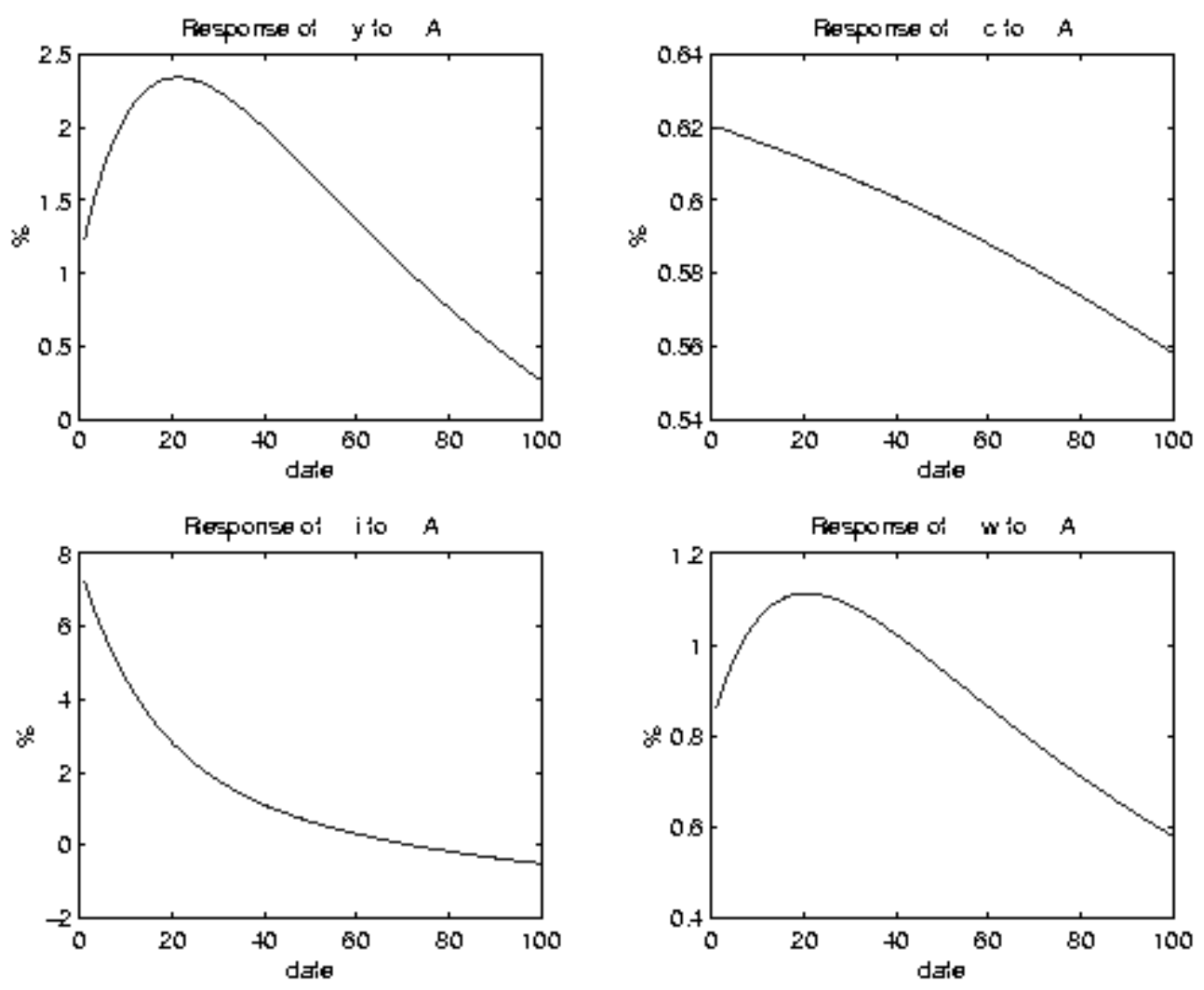

Figure 3: Selected Impulse Responses from Productivity Shock Model 

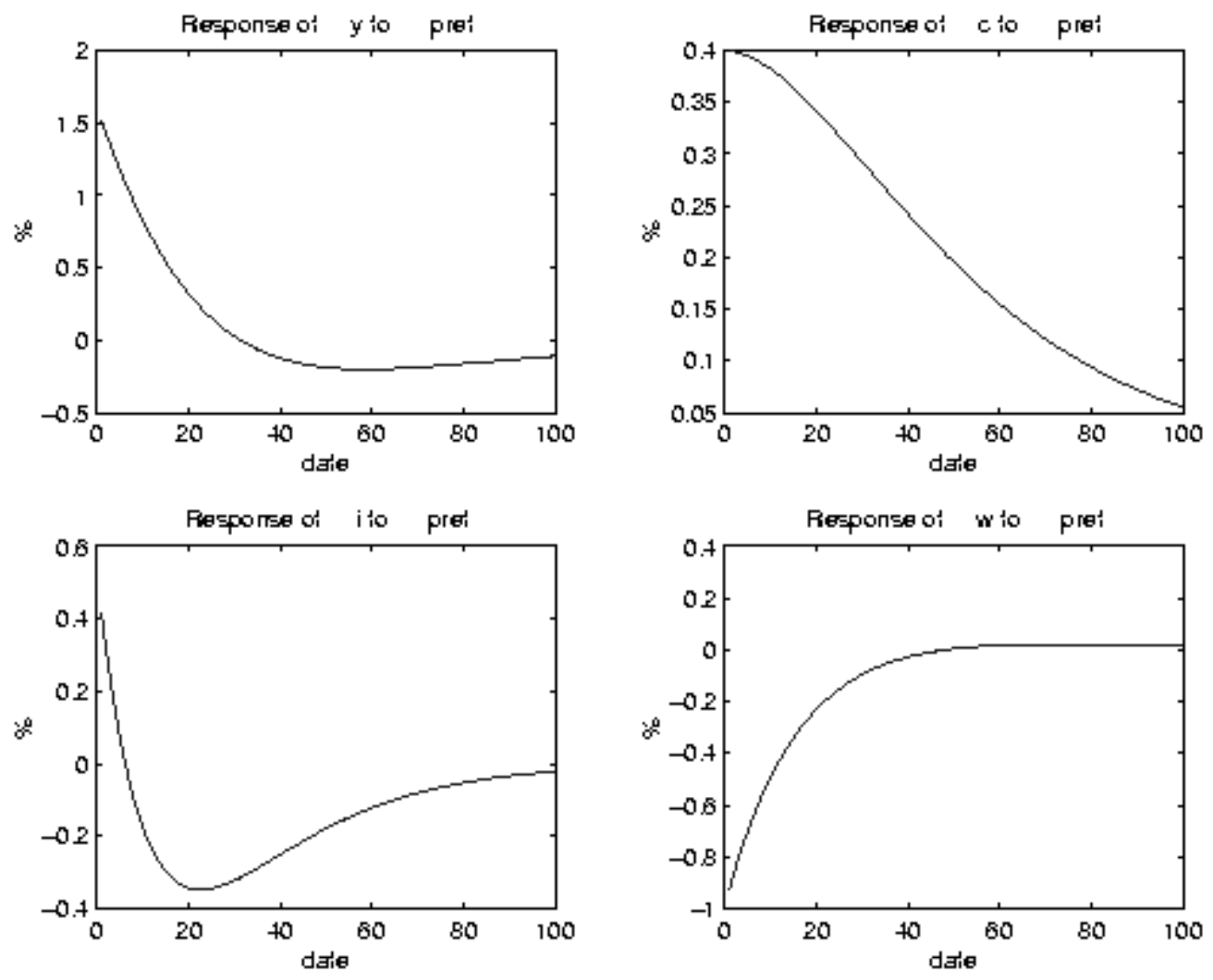

Figure 4: Selected Impulses from Preference Shock Model 
Correlations of data with output(k): productivity model
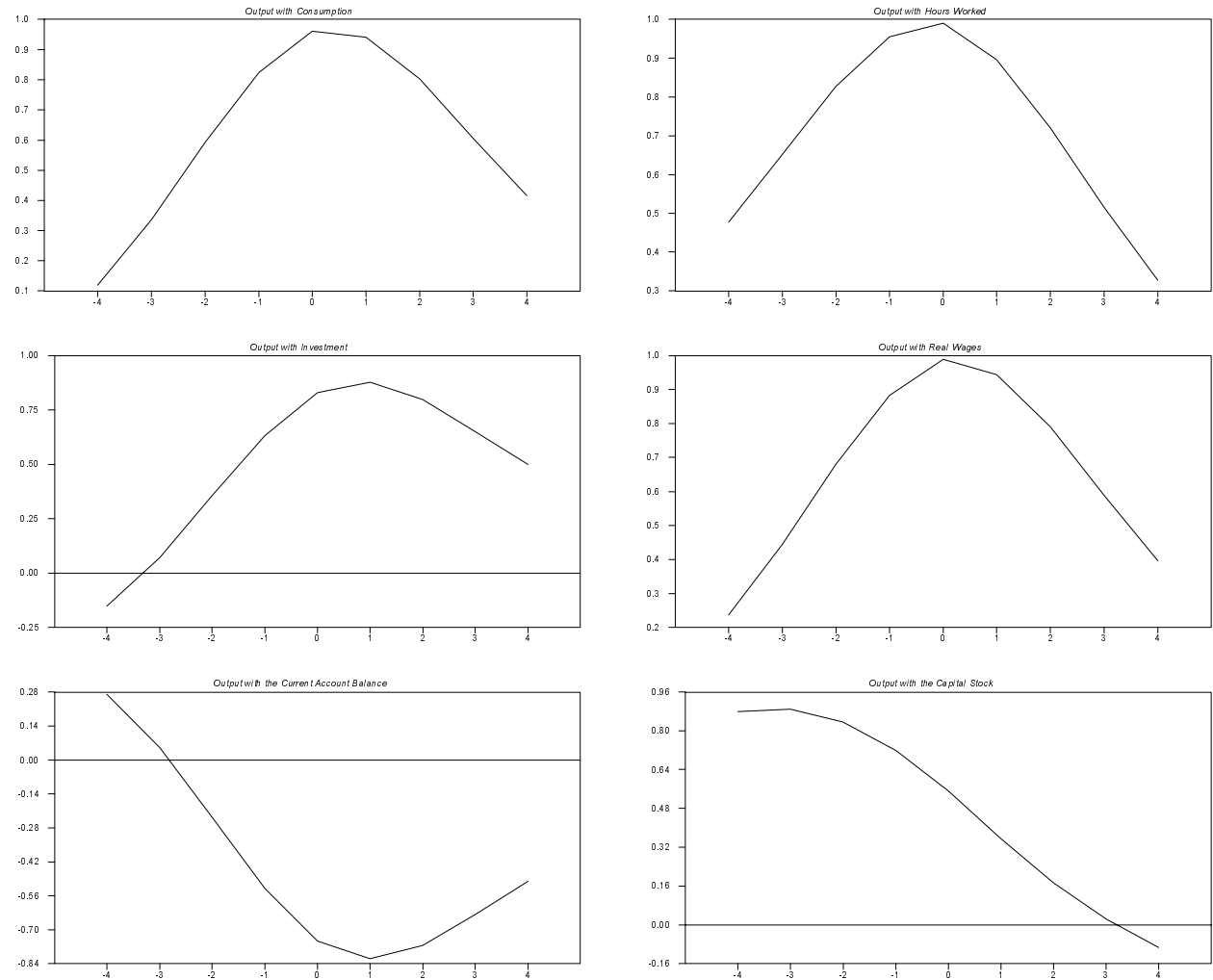

Figure 5: 
Correlations of data with output(k): preference model
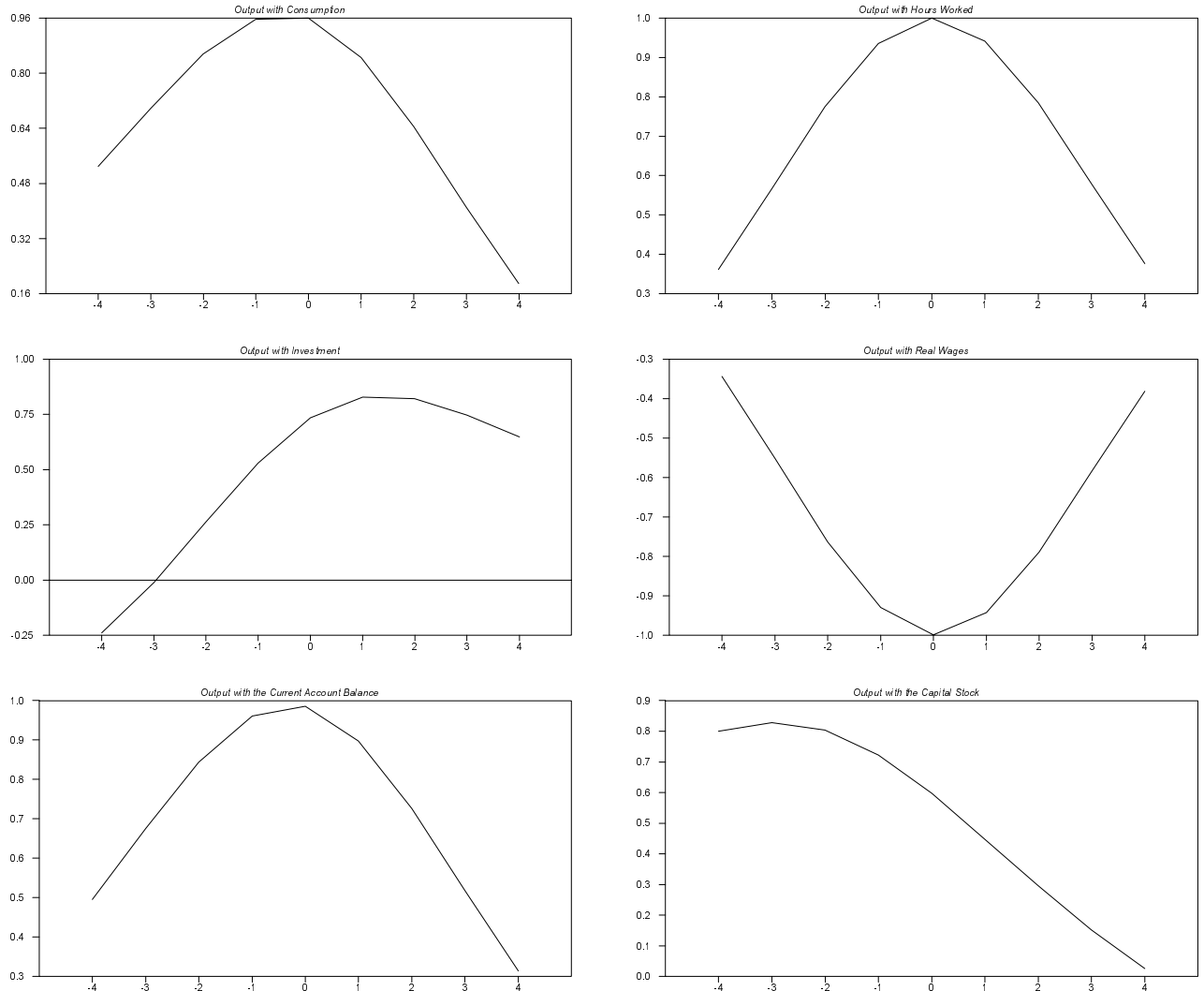

Figure 6: 


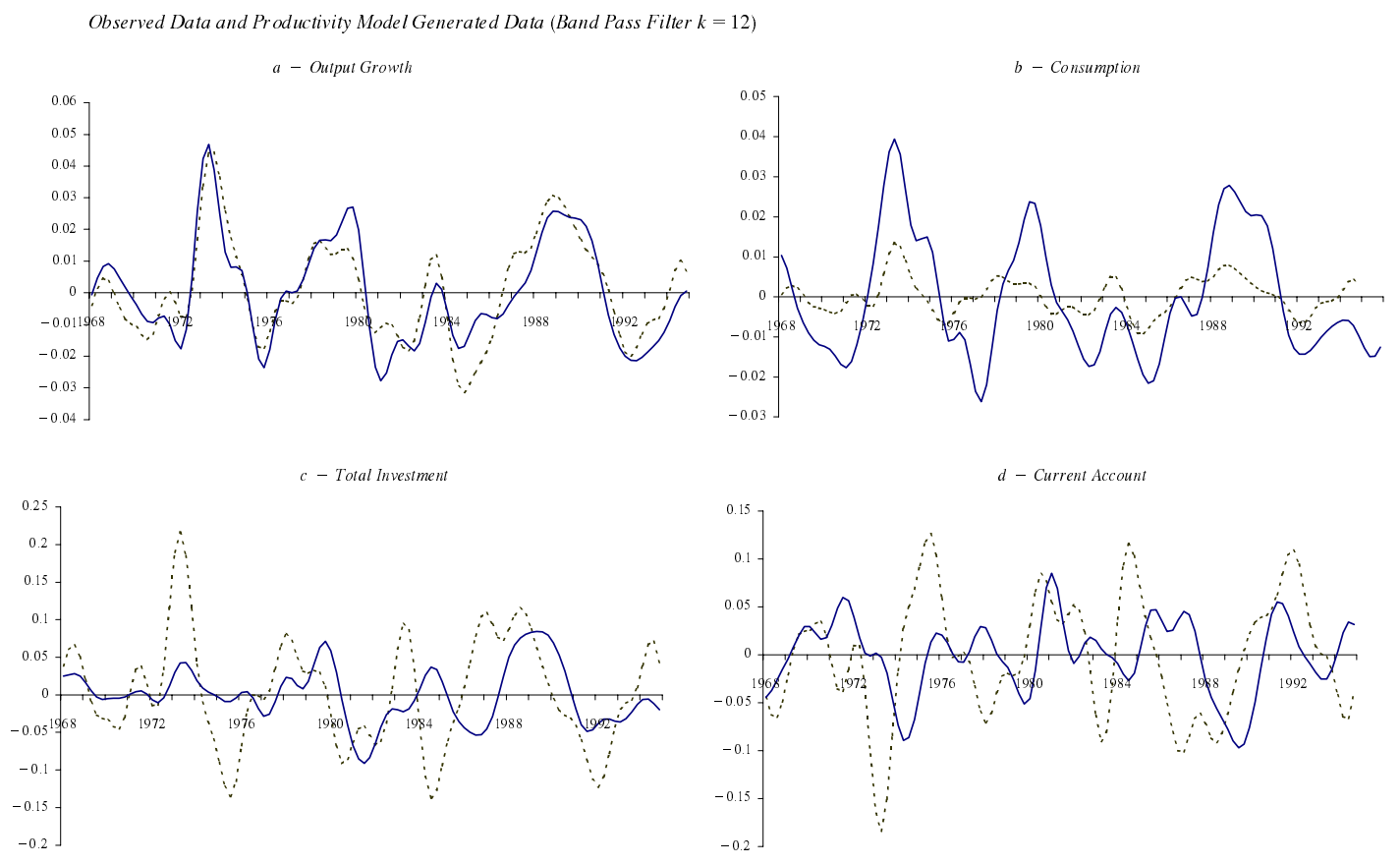

Figure 7: 
Ohsened Dataand Preference Model Generated Data (BandPass Filter k =12)
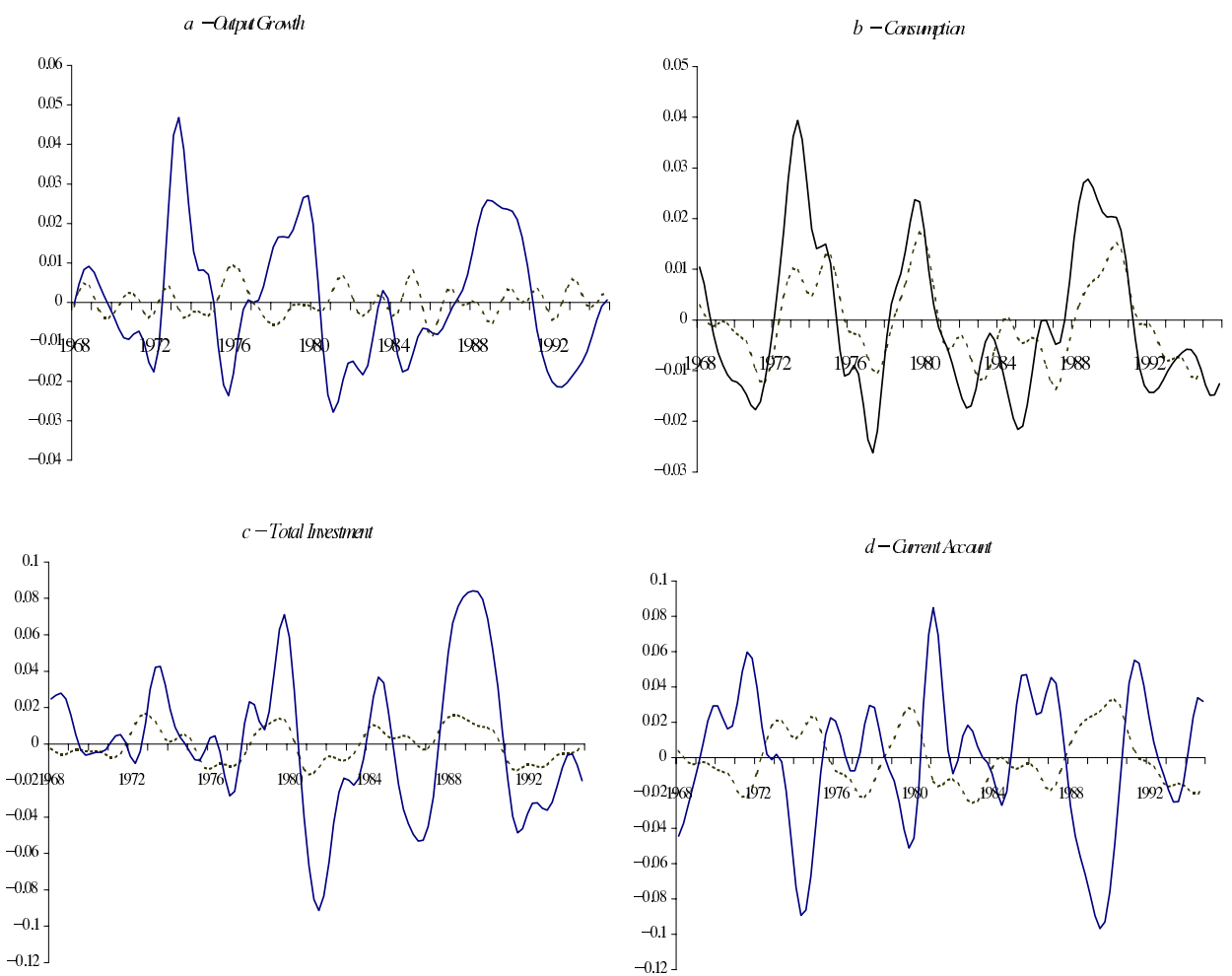

Figure 8: 